\title{
Typologies of intimate partner violence-maternal parenting and children's externalizing problems: The moderating effect of the exposure to other forms of family violence ${ }^{\text {it }}$
}

\author{
Diogo Lamela ${ }^{\mathrm{a}, *}$, Inês Jongenelen ${ }^{\mathrm{a}}$, Ricardo Pinto ${ }^{\mathrm{a}}$, Alytia Levendosky ${ }^{\mathrm{b}}$ \\ ${ }^{\text {a }}$ Lusófona University of Porto, Portugal \\ ${ }^{\mathrm{b}}$ Michigan State University, United States
}

\section{A R T I C L E I N F O}

\section{Keywords:}

Externalizing problems

Family violence

Intimate partner violence

Parenting

\begin{abstract}
A B S T R A C T
Typologies of IPV and parenting practices in mothers who experienced police-reported IPV remain surprisingly unexplored, in addition to how those typologies are linked with children's externalizing problems. Using data from 162 Portuguese mother-child dyads with a police or child protection services referral of IPV, this study aimed to: (a) identify IPV-parenting typologies; (b) test the associations between typologies and children's externalizing problems, and (c) examine the moderating effect of children's exposure to other forms of family violence in those associations. Using a person-centered approach, two IPV-parenting typologies were found: a spillover typology, with high levels of physical, psychological, and sexual violence and high levels of harsh and inconsistent parenting practices; and a compartmentalized typology, with high levels of physical, psychological, and sexual violence and lower ineffective parenting practices. Results also showed that externalizing symptoms (reported by mothers and teachers) were significantly lower in children of mothers in the compartmentalized typology compared to those in the spillover typology. Children's direct exposure to other forms of family violence moderated this association. Findings suggested that children with a high exposure to other forms of family violence showed the highest levels of externalizing problems when their mothers were classified into the spillover typology, and they exhibited the lowest levels of externalizing problems when their mothers were classified in the compartmentalized typology.
\end{abstract}

Children who are exposed to intimate partner violence (IPV) are at higher risk for not achieving age-appropriate emotional selfregulation skills and may instead exhibit problems in self-regulation, as exemplified by high levels of externalizing behavior (Gilbert et al., 2013; Vu et al., 2016). Multiple studies have documented that the experience of being raised in families with IPV contributes to children's higher risk of externalizing problems (Jouriles, Rosenfield et al., 2016; McFarlane et al., 2003), including oppositional behavior, aggression, impulsivity, cheating, hyperactivity, and inattention (Bauer et al., 2013; McFarlane et al., 2003).

Under the family systems framework, maternal parenting practices have been thought of as a major explanatory mechanism of the association between IPV and externalizing problems. The spillover hypothesis suggests that severe forms of marital conflict instigate mothers' negative emotional arousal and emotional dysregulation that in turn will be transferred to mother-child interactions (Kerig \& Swanson, 2010; Krishnakumar \& Buehler, 2000). In particular, marital conflict characterized by physical assault, psychological violence, and sexual coercion is thought to impair maternal self-regulation processes that ultimately disrupt parenting behaviors,

\footnotetext{
This research was supported by the Fundação para a Ciência e Tecnologia (EXPL/MHC-PED/1977/2013) awarded to Inês Jongenelen.

* Corresponding author at: Lusófona University of Porto, Rua Augusto Rosa, 24, 4000-098, Porto, Portugal.

E-mail address: lamela@ulp.pt (D. Lamela).
} 
increasing the odds of harsh or inconsistent parenting practices to manage children's behaviors and caregiving needs (Krishnakumar \& Buehler, 2000). As a result, offspring would exhibit higher levels of self-regulation problems. Consistent with the spillover hypothesis, several studies have shown longitudinal and mediating associations between IPV, ineffective parenting, and children's externalizing problems (Easterbrooks et al., 2018; Grasso et al., 2016; Levendosky et al., 2006; Manning et al., 2014; Vu et al., 2016).

However, a growing body of research has also revealed no significant associations between IPV victimization and maternal ineffective parenting practices, and, in some cases, IPV is linked with more effective parenting practices and subsequent lower levels of externalizing problems (Casanueva et al., 2008; Graham-Bermann et al., 2009; Levendosky et al., 2003; Sturge-Apple et al., 2014). Consistent with these studies, the compartmentalization hypothesis posits that mothers exposed to high levels of marital conflict are able to separate marital and parenting roles (Krishnakumar \& Buehler, 2000). In contrast with the spillover hypothesis, the compartmentalization hypothesis asserts that mothers are competent in containing hostility, anger, and negative affectivity inside the boundaries of the marital subsystem by isolating the negativity of marital relationship from child-mother interactions. Thus, regardless of exposure to IPV, mothers are able to engage in effective parenting practices, buffering the detrimental impact of marital conflict on children's psychological adjustment (Erel \& Burman, 1995).

Both models have been compared empirically, and stronger evidence for the spillover hypothesis in families with high interparental conflict has been found across different samples (Ehrensaft et al., 2017; Grasso et al., 2016; Krishnakumar \& Buehler, 2000). However, the spillover and compartmentalizing processes may not be competing models to predict children's mental health, but instead are concurrent processes that may co-occur naturally in population. This co-occurrence may be underestimated in the literature due to methodological reasons. With few exceptions, previous research has been conducted using variable-centered approaches that might prevent the detection of multiple configurations of co-occurrence between IPV and parenting practices in the prediction of children's externalizing problems. By assuming population homogeneity in the associations between variables, variablebased research only provides information for an average person in the sample (Bergman \& Andersson, 2010; Masyn, 2013). This information can be translated for a particular person into a probability based only on average information about all individuals in the sample (Masyn, 2013; Rupp, 2013). As such analyses are largely grounded on the examination of mean level differences between individuals, the inspection of the differential strength and direction of the associations between IPV and parenting practices is potentially compromised. For example, if in a hypothetical sample a large group of participants exhibited a weak and positive association between IPV exposure and parenting problems and a small group a strong negative association, mean-based statistical approaches would likely fail to detect any association between those variables. In addition, this implied assumption of population homogeneity with the respect of the relationship between variables precludes the capture of the complex and dynamic configuration of factors within individuals. As a result, this approach prevents the existence of subpopulations with distinct patterns of ratings and thus the detection of less prevalent groups in the population.

Alternatively, person-centered approaches describe similarities and differences among individuals instead of relations among variables (Bergman \& Andersson, 2010; von Eye \& Bergman, 2003). This approach focuses on classifying individuals into homogeneous subgroups characterized by a similar pattern of associations among variables (Rupp, 2013). By assuming population heterogeneity in the relationships between variables, multiple configurations of IPV-parenting practices may be potentially extracted from the data (Masyn, 2013). As a result, extraction of relatively homogeneous subgroups based on individuals' characteristics is potentially more sensitive for the detection of less prevalent groups. Thus, these person-centered procedures may have clinical utility for the understanding of how the interplay between IPV and parenting practices are associated with higher risk of externalizing problems in children. In particular, identifying how multiple IPV-parenting typologies can be differentially associated with children's externalizing problems is essential to the development of selective preventive interventions for specific subgroups of mothers whose children reported a higher risk of externalizing difficulties.

Although empirical work has demonstrated the value of these pattern-centered approaches to filter typologies of family functioning (Belsky \& Fearon, 2004; Lamela et al., 2016), the identification of IPV-parenting typologies in families with police-identified IPV is yet to be explored. One exception was a study conducted with an American community sample of mothers of toddlers that found three typologies of IPV-parenting practices (Sturge-Apple et al., 2014): a group with high levels of physical and psychological IPV coupled with high levels of maternal harsh and insensitive parenting and low warmth, described as spillover families; a group with moderate-to-high levels of physical and psychological IPV, low levels of maternal harsh and insensitive parenting, and high warmth, labelled as compartmentalized families; and a group that displayed low levels of physical and psychological IPV, low levels of maternal harsh parenting, and average levels of maternal warmth, classified as adequate families. This study reported inconclusive findings regarding the association between IPV-parenting typologies and children's externalizing problems. Specifically, although children of mothers in the spillover group exhibited the highest levels of externalizing symptoms at the baseline assessment, no significant differences between spillover and compartmentalized typologies were found one year later (Sturge-Apple et al., 2014).

Regardless of the contribution of the seminal study of Sturge-Apple et al. (2014) in the understanding of the associations between IPV-parenting typologies and externalizing problems, questions remain about how those typologies may be generalizable to at highrisk mothers exposed to multiple forms of IPV and also their replicability in other cultures. Specifically, it is unclear whether those typologies of IPV-parenting would be generalized to women who experienced police-reported male-perpetrated IPV. Differences in these associations may emerge between self-reported IPV and police-reported IPV (Capaldi et al., 2012). In particular, past studies have shown that the police reporting behavior is influenced by women's social risk status, the presence of a child during the incident, and the severity of the IPV event (Akers \& Kaukinen, 2009; Campbell et al., 2017; Sanz-Barbero et al., 2016). For example, Akers and Kaukinen (2009), using data from a Canadian representative survey, found that only $33 \%$ of women who self-reported being exposed to IPV in the survey have reported the IPV incident to the police. When compared to those women with no IPV police report, this study showed that women who reported the IPV to the police were more likely to have a children involved in the IPV incident and to 
have been exposed to multiple forms of violence simultaneously and/or to severe forms of physical violence (e.g., threats with weapons, injury, and the destruction of their property), (Akers \& Kaukinen, 2009). Similar results were found in other representative national surveys (e.g., Sanz-Barbero et al., 2016). Taken together, these findings have suggested that the police-reporting cases of IPV may be associated with more aggressive and life-threatening experiences of IPV. As higher IPV severity has been, in turn, associated with greater maternal psychopathology symptoms and higher disruptive parenting behaviors (e.g., Green, Chan, McCarthy, Wakschlag, \& Briggs-Gowan 2018), it is plausible to hypothesize that the number of IPV-parenting typologies, typologies' defining features, and the distribution of cases per typology might differ between community samples with self-reported IPV and high-risk samples with police-reported IPV. Testing IPV-parenting typologies with documented police-reported IPV would, therefore, provide additional insights regarding whether these typologies are generalizable to all women, regardless the method of assessment of IPV.

Second, Sturge-Apple et al.'s (2014) study only considered physical and psychological forms of IPV, excluding the examination of sexual coercion. Recent research has, however, shown the detrimental interplay of sexual coercion and physical and psychological violence in the prediction of children's externalizing problems (Jouriles, McDonald et al., 2016; Jouriles, Rosenfield et al., 2016). As sexual coercion may exert a significant pressure on maternal psychological well-being and jeopardize maternal parenting practices, a further examination of multiple configurations of physical, psychological, and sexual violence would offer a better portrait of how multiple forms of IPV may interact with maternal parenting practices.

Finally, Sturge-Apple's et al. (2014) study was conducted with an American sample and empirical replication of those typologies with culturally distinct samples was yet to be explored. However, a large body of research has documented substantial cultural/ country variability in attitudes toward against women, IPV prevalence, public responses to IPV, and attitudes toward parents' disciplinary practices (e.g., Costa et al., 2015; Gracia \& Herrero, 2008), it might be expected that the association between IPV-parenting typologies and children's externalizing problems could be (at least partially) culturally influenced. Having Portugal as example, the country has experiencing significant cultural changes regarding attitudes against IPV, IPV prevalence, and IPV legislation (Alves et al., 2016). In the last decade, substantial improvements were made in legal protection and formal social support to the IPV victims, including a new law providing free health care for victims of IPV (introduced in 2007) and changes in the same year to the Portuguese Criminal Code making IPV punishable by up to five years in prison. These political initiatives to raise public awareness and improve the legislation concerning to IPV have permitted to Portugal to achieve a similar prevalence of past year IPV than the average of the European Union countries (8\%) (European Union Agency for Fundamental Rights, 2014). In addition, data from a large European survey designed to describe and compare the IPV attitudes among 27 European Union countries revealed that Portuguese respondents showed one of the strongest attitudes against IPV, the highest perception of social support to IPV victims, and one of the highest perception about of special laws and prevention against IPV (Eurobarometer, \& European Comission, 2010). Although extensive research has been carried out on IPV dynamics, just a single study has examined the prevalence of behaviors and attitudes toward ineffective parenting practices in Portugal (Machado et al., 2007). Results from this large community-based, self-reported study showed that $12.3 \%$ of parents reported at least one act of physical punishment in the last year and $66.8 \%$ of parents strongly or moderately disagreed with use of physical punishment (Machado et al., 2007). More recently, a large community-based study with Portuguese parents found a small effect in the odds of using physical punishment by parents with childhood history of harsh parenting (71\% of the participants) when compared with the odds of parents with no exposure to physical abusive practices in childhood (Lamela \& Figueiredo, 2018). This result suggests a disruption in the intergenerational transmission of harsh parenting practices, suggesting that a substantial cultural change in parenting practices is taking place in Portugal (Machado et al., 2007). Despite sharing similar indicators of social development with USA (e.g., both countries are classified as high income and high social progress countries), Portugal presents discrepant trends in prevalence of IPV and child corporal punishment (used here as an indicator of ineffective parenting). While prevalence of lifetime physical/sexual IPV in Portugal (19\%) is lower than USA (37\%) (European Union Agency for Fundamental Rights, 2014; Smith et al., 2017), the prevalence of use of corporal punishment by a caregiver in the past year was higher in Portugal (12.3\%) than in USA (5\%) (Finkelhor et al., 2015; Machado et al., 2007). Taking into account these cultural differences, testing the IPV-parenting typologies in Portuguese context might contribute to additional insights about whether typologies and their association with children's externalizing problems might be influenced by culture-specific factors.

\section{Children's exposure to other forms of family violence as a moderator}

To provide additional insight into the associations between IPV-parenting typologies and children's externalizing problems, it is also crucial to consider individual differences that might increase children's experiences of deeper externalizing difficulties in the IPV context. Associations between IPV-parenting typologies and externalizing problems should depend in part on individual differences in children's direct exposure to other forms of family violence, defined here as witnessing acts of physical and/or psychological violence between family members or seeing the effects of those violent acts (e.g., injuries) (Fox \& Leavitt, 1996). Specifically, higher direct exposure to other forms of family violence might exacerbate the effect of high levels of IPV and ineffective parenting practices on children's externalizing problems.

Although family environments characterized by IPV and ineffective parenting practices are a major source of stress for all children (Vu et al., 2016), the frequency of direct exposure to other forms of violent behaviors within the family (between siblings, parentsibling, other relatives) beyond IPV may be a significant variable to take into account when studying individual differences in externalizing problems, as suggested by previous research.

Empirical work has indicated high levels of co-occurrence of children's exposure to IPV and other forms of family violence (Hamby et al., 2010; Miller et al., 2012). For example, Hamby et al. (2010) found that while 3.3\% of children that were not exposed to IPV reported to have witnessed a violent act between other family members, $20 \%$ of children exposed to IPV reported to have also 
witnessed other forms of family violence. In addition to the significant co-occurrence of children's exposure to multiple forms of family violence, a common assumption of evolutionary-developmental, family systems, and neurobiological models of family conflict is that the overexposure to multiple forms of family violence may impair children's psychological and neurobiological self-regulatory processes and ultimately increase their risk for self-regulation problems (Davies \& Martin, 2014; Ellis et al., 2011; Kerig \& Swanson, 2010). This theoretical consistency across different conceptual models raises the possibility that direct exposure to additional forms of family violence may moderate associations between IPV-parenting practices typologies and children's externalizing problems.

To our knowledge, no previous research tested this hypothesis directly. However, there are two potential empirically-driven explanations of why direct exposure to other forms of family violence might moderate the association between IPV-parenting practices and children's externalizing problems, particularly in spillover families. First, the co-occurrence of IPV and other violent behaviors between family members (e.g., siblings, grandparents) may indicate that the family environment is not operating as a protective factor amidst the negative effects of IPV-ineffective parenting practices on children's mental health. Previous work suggests that positive family processes (e.g., family warmth, family cohesion, family social support, overall protective family environment) have a significant buffering effect against the exposure to violence on externalizing behaviors (Houltberg et al., 2012; Miller et al., 1999). Second, direct exposure to violence among other family members might be particularly detrimental to children's emotional self-regulation in spillover families, since the family is interpreted as an even more threating, unpredictable, and harmful environment. According to the evolutionary-developmental perspective of adaptative development (Ellis et al., 2011), the emergence of anger-based and violent behaviors in children are thought as developmental adaptations to high-violent environments to allow them to competently survive in these harsh and poor-resourced conditions (Ellis et al., 2011). These strategies are adaptive in order to mitigate the short-term impact of adverse environments, but they have long-term developmental costs, including externalizing problems. Therefore, the cumulative occurrence of IPV, harsh parenting, and other forms of violence between family members may intensify the need for aggressive, noncompliant, and oppositional behaviors as adaptive strategies to function competently in a highstress environment. Consistent with this rationale, it is plausible that direct exposure to other forms of family violence beyond IPV might exert a moderating effect on the association between IPV-parenting typologies and children's externalizing problems.

\section{The current study}

The present research had three aims. First, we sought to identify IPV-parenting practices typologies in Portuguese mothers who were victims of IPV through applying cluster analyses procedures. Physical, psychological, and sexual violence and harsh and inconsistent parenting practices were utilized as clustering variables. We hypothesized that two distinct clusters (i.e., typologies) would be found: a cluster with high levels of physical, psychological, and sexual violence and high levels of harsh and inconsistent parenting, and a cluster with high levels of physical, psychological, and sexual violence and low levels of harsh and inconsistent parenting practices. In contrast with previous research with community mothers that found a third cluster characterized by moderate to low levels of IPV and low ineffective parenting practices (Sturge-Apple et al., 2014), we hypothesized that such a cluster would not be found in mothers with current or recent episodes of IPV.

Second, we investigated whether the IPV-parenting typologies would be associated with children's externalizing problems (reported by mothers and teachers). We hypothesized that family environments characterized by high levels of IPV and high levels of harsh and inconsistent parenting would be greatly associated with higher levels of externalizing problems when compared with family environments characterized by high levels of IPV but low harsh and inconsistent parenting practices.

Finally, we tested whether individual differences in children's direct exposure to other forms of family violence would moderate the relation between IPV-parenting practices and children's externalizing problems. We anticipated that children of mothers with high IPV and ineffective parenting would exhibit the highest levels of externalizing problems at high levels of direct exposure to family violence.

\section{Method}

\subsection{Participants}

Participants consisted of Portuguese 162 mothers and their children aged between 4 to 10 years. Mothers had to have experienced police-reported male-perpetrated IPV during the last year. Participants were recruited from Child Protective Services and shelter residences from north to south of Portugal. Additional inclusion criteria were as follows: (a) mothers had to be at least 18 years old; (b) the child must be living with the mother, either at home with the abusive partner, or in the IPV shelter; and (c) the child must not have a diagnosed cognitive or sensory disorder/dysfunction.

The mothers' mean age was 36.49 years $(S D=7.68$; range $=21-58)$. With respect to marital status, $60 \%$ of the sample were married or in cohabitation, $19.8 \%$ were divorced, and $20.2 \%$ were single or widowed. Eighty-five mothers (52.4\%) did not complete a 9th-grade compulsory education level, 58 had completed the compulsory education level, 13 had completed a high school education, and 4 mothers (2.5\%) had a college degree. Most mothers (75\%) were unemployed or had never worked, and $48 \%$ received public social benefits. The mean age of the children was 7.23 years $(S D=1.94)$, with $54 \%$ of the sample consisting of boys $(n=87)$. 


\subsection{Measures}

\subsubsection{Intimate partner violence}

Thirty-nine victimization items from the Revised Conflict Tactics Scales (CTS2; Straus et al., 1996) were used to measure participants' victimization experiences of physical aggression with injuries, psychological aggression and sexual coercion by an intimate partner over the past year. The CTS2 is the most widely used self-report measure for assessing IPV and has good reliability and validity. The CTS2 is scored by summing the frequency of each of the behaviors for each subscale, with higher scores indicating more frequent aggression. Responses were made on a 6-point Likert-type scale ranging from never to more than 20 times. The physical assault subscale includes twelve items, (e.g., "beat up my partner"). The 6-item injury subscale assesses how often certain types of injury occurred as a result of physical assault by an intimate partner. The psychological aggression subscale contains eight items assessing participants' verbal and psychological forms of victimization. The 7-item sexual coercion subscale measures respondents' exposure to threats or force to coerce unwanted sexual activity. For the current study, a composite score of physical violence with injury was computed by summing physical assault and injury subscales. The Portuguese version of the CTS2 revealed good psychometric properties (Paiva \& Figueiredo, 2006). For the current sample, coefficient alpha for the physical violence, psychological aggression, and sexual coercion subscales was $.86, .90$, and .89 , respectively.

\subsubsection{Maternal harsh parenting}

Harsh parenting was assessed with the overreactivity subscale of the Parenting Scale (PPS; Arnold et al., 1993). This 9-item subscale measures parents' tendency to respond with harsh and coercive discipline to children's problematic behavior, such as anger, frustration, meanness and irritation, impatience, and the use of physical punishment. Each item is rated on a 7-point Likert scale (from 0 'never' to 6 'always'). Higher scores reflect higher harsh parenting. Previous work showed that Parenting Scale scores were significantly associated with observational measures of dysfunctional discipline (Arnold et al., 1993). Good psychometric properties were found in the PPS Portuguese version (Cruz et al., 2011). For the current sample, Cronbach's alpha was .74.

\subsubsection{Maternal inconsistent parenting}

Inconsistent parenting was assessed with the laxness subscale of the Parenting Scale (PPS; Arnold et al., 1993). This subscale measures parents' inconsistent parenting practices defined by difficulties in control child misbehavior, low enforcement of rules and authority and low persistence in discipline strategies. The subscale consists of eleven items assessing the extent to which parents engaged in specific permissive discipline responses that are rated on a 7-point scale (from 0 'never' to 6 'always'). Higher scores reflect higher inconsistent parenting. Good psychometric properties were found in the PPS Portuguese version (Cruz et al., 2011). For the current sample, Cronbach's alpha was .77.

\subsubsection{Maternal depression symptoms}

Depression symptoms were assessed by the depression scale of the Brief Symptom Inventory (BSI; Derogatis \& Melisaratos, 1983). This 6-item scale measures individuals' depressed mood, sadness, loss of interest in life activities, unworthiness/worthlessness, hopelessness, loneliness, and vulnerability to criticism. Respondents are asked to answer regarding their levels of distress over the previous two weeks, using a 5-point Likert-scale (from 0 'not at all' to 4 'extremely'). Higher scores reflect higher depression symptoms. Previous empirical work revealed that the BSI depression scale as a reliable and valid measure for screening depression symptoms (Callender et al., 2012). The Portuguese version of the depression scale of the BSI revealed good internal consistency (Canavarro, 1999). In the current sample, Cronbach's alpha was .82.

\subsubsection{Children's exposure to other forms of family violence}

Children's exposure to other forms of family violence was measured using the Violence Exposure Scale for Children-Revised (VEXR; Fox \& Leavitt, 1996). Using a cartoon format, this 21-item child self-report measure depicts cards to children with illustrations of violent and criminal acts and asked them to describe the frequency of their own exposure to those acts, either as a victim or witness. Depicted violent and criminal acts range in severity from relatively mild (e.g., being yelled at, pushed, or spanked) to relatively severe (e.g., being threatened with a weapon, shot, or stabbed). Designed for use with respondents ages 4-10, the frequency of exposure is rated on a four-point scale $(0=$ never, $1=$ once, $2=$ a few times, and $3=$ lots of times). As we were exclusively interested in examining the moderation effect of children's observed (i.e., witnessed) other forms of family violence, only items that particularly measure children's exposure to family violence as a witness were administered. Children were asked to answer based their witnessing of violent behavior between other family members (e.g., between siblings, parent-sibling, other relatives), beyond mother-intimate partner violence. Trained examiners administered the VEX-R to children face-to-face. The Portuguese version of the VEX-R revealed adequate psychometric properties (Sousa, 2015). The Cronbach's alpha reliability in the current sample was .80.

\subsubsection{Children's externalizing problems}

Externalizing problems were measured with the Strengths and Difficulties Questionnaire - Parent and Teacher Forms (SDQ; R. Goodman, 1997). This 25-item highly valid screening measure cover children's strengths and psychological problems in five subscales: hyperactivity/inattention, conduct problems, emotional symptoms, peer problems, and prosociality. Items are rated on a 3point response scale (from 0 'not true' to 2 'certainly true'), with each subscale constructed as the sum of five items (maximum score $=10$ ). Consistent with Goodman (A. Goodman et al., 2010), externalizing problems were measured by computing a composite score obtained from the sum of the scores of two SDQ subscales: hyperactivity/inattention and conduct problems. Higher scores 
reflect higher externalizing problems. This procedure was used for both mother and teacher reports. The Portuguese version of the SDQ revealed adequate psychometric properties (Marzocchi et al., 2004). The Cronbach's alpha reliabilities for the Externalizing Problems composite were .72 (mothers-form) and .75 (teacher-form).

\subsection{Procedures}

Participants were recruited from 12 Child Protective Services and 117 institutions that provide assistance to female victims of IPV and agreed to contact mother-child dyads that met the inclusion criteria. Professionals of these institutions first approached potential participants and provided information about research aims and ethical procedures. In total, 352 mothers were contacted by the professionals, and 162 mothers agreed to participate. Interviews were then scheduled with mothers who consented to participate, and additional information regarding the study's methods and confidentiality procedures was extensively discussed. After written informed consent was obtained, trained female research assistants administered the assessment protocol in Child Protective Services or shelters facilities. Mothers received vouchers from a local department store in appreciation for their participation. To collect teacher ratings of children's externalizing problems, teachers were contacted by telephone and invited to participate in the study. The SDQ was sent by e-mail to the teacher of each child who participated, and $58(38.1 \%)$ were successfully returned. No significant differences were found between participating and nonparticipating teachers in children's age, $t(160)=-0.853$, ns, and children's gender, $\chi^{2}(1)=1.94, n s$. The research procedures were approved by the Portuguese Data Protection Authority and by the institutional review board at the research site prior to conducting the study.

\subsection{Data analysis strategy}

Firstly, cluster analytic procedures were performed in order to identify IPV-parenting practices typologies. Clusters were constructed using three scales of CTS2, and the Overreactivity and Laxness subscales of the Parenting Scale were used as the criteria for similarity versus dissimilarity. Initially, a Ward's agglomerative hierarchical cluster analysis (Standardized Euclidian Distance method) was conducted in order to establish the number of clusters. The visual inspection of the hierarchical cluster analysis outputs (e.g., dendrogram analysis, Euclidian distance plot, and agglomeration scheme) was used to determine the optimal clustering solution. To confirm this solution, cases were then cluster-analyzed by performing the widely used $K$-means procedure with squared Euclidean distance as index of similarity (z-scores of the CTS2 and Parenting Scale subscales were employed). The comparison of the results from the $K$-means analysis with those obtained in the hierarchical cluster analysis was performed using Cohen's Kappa coefficient as an agreement measure (Hoeve et al., 2008). The final cluster solution was selected based on kappa values and theoretical interpretation. Stability of the cluster solution was tested using a cross-validation procedure (Mandara, 2003). After randomly splitting the overall sample into two subsamples, a $K$-means analysis was conducted on both subsamples, and the agreement between the two solutions was calculated using Cohen's Kappa coefficient. This procedure was replicated ten times (Hoeve et al., 2008).

The $K$-means procedure was adopted to perform cluster analysis over the latent profile analysis (LPA) for three main methodological reasons. First, no significant differences were found between the empirically derived clusters in their variances in all clustering variables (for physical violence, Levene's $W=0.56, p=.45$; psychological violence, Levene's $W=2.58, p=.11$; sexual coercion, $0.62, p=.43$; harsh parenting, Levene's $W=0.34, p=.56$; and inconsistent parenting, $0.01, p=.99$ ), suggesting the use of the $k$ means procedure. Second, the Shapiro-Wilk and Kolmogorov-Smirnov tests suggested that all clustering variables were not normally distributed, violating the LPA assumption of normality (Shapiro-Wilk: ps. $<.0001$ for the two clusters; Kolmogorov-Smirnov: ps. $<.001$ for both clusters). Third, the $K$-means procedure exhibited higher separation of fit to the data. Specifically, we used five clustering quality indices to empirically compare clustering results based on the $K$-means and the LPA: Silhouette, C-index, Calinski, Gamma, and Davies Bouldin (Guerra et al., 2012; Milligan \& Cooper, 1985; Zilcha-Mano et al., 2015). Most of these indices corroborated the use of $K$-means with the current data. Globally, these preliminary analyses suggested the data appeared to be more compatible with the $K$-means assumptions than the LPA assumptions. We have subsequently conducted a LPA to explore whether the optimal cluster solution found via $K$-means procedure would be replicated and confirmed by LPA. We estimated four profile models and compared them using three information criteria-based fit measures. By examining the goodness-of-fit indexes of the four estimated models, our results indicated that typologies identified by LPA were consistent with those found with $K$-means cluster analysis, in terms of the optimal number of typologies, the most salient dimensions of each typology, and also the distribution of participants per typology. The LPA procedures and results are described in the Supplementary Material.

Next, additional one-way analyses of variance and chi-square tests were conducted to test differences between the IPV-parenting groups in socio-demographic and divorce variables. Finally, hierarchical multiple regression analyses were conducted to test the hypotheses that clusters would predict externalizing problems (hypothesis 2) and children's exposure to family violence would moderate the association between partner violence-parenting clusters and externalizing problems (hypothesis 3). Two separate regression analyses were conducted predicting externalizing symptoms according to mother-reported and teacher-reported scores, respectively. Before examining the main and moderation effects, all variables were centered in order to reduce collinearity (Aiken et al., 1991; Frazier et al., 2004). For each regression analysis, child age, child gender (coded as $0=$ girls vs. $1=$ boys), and maternal depression symptoms were entered as covariate variables in Step 1. In Step 2, partner violence-parenting typologies were added as the predictor variable (coded as $0=$ spillover cluster vs. $1=$ compartmentalized cluster). Step 3 included children's exposure to family violence as the moderator variable. Finally, in Step 4, the product term of the interaction of the predictor and the moderator was added (IVP-parenting typologies $\times$ children's exposure to other forms of family violence). The interaction between predictor and moderator was examined and interpreted using simple slope analyses (Aiken et al., 1991). Slope difference tests were also computed 
Table 1

Results of t-tests and Descriptive Statistics CTS2 and PA Subscales by Typology.

\begin{tabular}{|c|c|c|c|c|c|c|}
\hline \multirow[t]{3}{*}{ Clustering variable } & \multicolumn{6}{|c|}{ Typology } \\
\hline & \multicolumn{2}{|c|}{ Spillover $(n=84)$} & \multicolumn{2}{|c|}{ Compartmentalized $(n=78)$} & \multirow[t]{2}{*}{$t(2,160)$} & \multirow[t]{2}{*}{ Cohen's $d$} \\
\hline & $M$ & $S D$ & $M$ & $S D$ & & \\
\hline CTS2 Physical violence with injury & 0.13 & 1.01 & -0.14 & 0.97 & 1.68 & 0.27 \\
\hline CTS2 Psychological violence & 0.18 & 0.97 & -0.19 & 1.00 & $2.43^{* *}$ & 0.37 \\
\hline CTS2 Sexual Coercion & 0.13 & 0.94 & -0.14 & 1.04 & 1.78 & 0.27 \\
\hline Maternal harsh parenting & 0.65 & 0.72 & -0.70 & 0.76 & $11.66^{\text {k.k.k. }}$ & 1.82 \\
\hline Maternal inconsistent parenting & 0.66 & 0.69 & -0.71 & 0.78 & $11.82^{k * k \times k}$ & 1.86 \\
\hline
\end{tabular}

$* * p<.01$.

$* * * p<0.001$.

to probe the two-way interaction effect. Such tests examined whether differences between slopes were significantly different from zero (Dawson \& Richter, 2006). The simple slope analyses with children's exposure to other forms of family violence as the moderator variable were conducted using an online-based utilities program (Dawson \& Richter, 2006; http://www.jeremydawson.co.uk/slopes. htm). The statistical analyses were performed using IBM SPSS 23 and LPA was carried out using Stata 15 (StataCorp. 2017 ).

\section{Results}

\subsection{Identifying typologies}

Standardized scores of the CTS2 and Parenting Scale subscales were cluster-analyzed to examine the possibility of intimate violence-parenting typologies. Analyses of dendrogram analysis, Euclidian distance plot, and agglomeration scheme from the Ward's agglomerative hierarchical cluster analysis indicated the adoption of two clusters as an optimal solution. As a confirmatory analysis, the comparison of the results of the $K$-means analysis with those obtained in the hierarchical cluster analysis revealed a very strong agreement $(\kappa=0.84)$. Based on the robust replication across both clustering procedures, the two-cluster solution was retained for all subsequent analyses (Rupp, 2013). The analyses of cross-validation for examination of the clusters solution stability revealed a substantial agreement for the three-cluster solution $(\kappa=0.75$, range: $0.57-0.92)$.

\subsubsection{Defining typologies}

Table 1 presents the means and standard deviations for standardized clustering variables for each of the two clusters, as well as the cluster-by-cluster differences. The two clusters were labeled based on the most salient dimensions. Mothers in cluster 1 (51.9\% of the sample) reported high levels of exposure to physical, psychological, and sexual violence along with high levels of maternal harsh and inconsistent parenting practices. This cluster was labeled as spillover typology. Cluster 2 (48.1\% of the total sample) displayed high levels of physical and sexual violence, relatively high levels of exposure psychological violence, and low levels of maternal harsh and inconsistent parenting practices. Based on these scores and no significant correlations between the intimate partner violence and parenting measures ( $p$ s. $>.05$; analyses not shown), this cluster was classified as compartmentalized typology.

\subsubsection{Comparisons on socio-demographic variables}

Next, we conducted a series of $t$-tests to examine whether typologies would differ on socio-demographic variables. No significant differences were found between groups in maternal age and years of education or number of children and focal child age (all ps. $>$.05). No significant difference was found between mothers living in shelters and mothers living with the abuse partner in the typology membership, $\chi^{2}(1,161)=0.176, n s$, Cramer's $V=0.10, n s$. A significant typology difference for focal child gender was found, with a higher proportion of boys in the spillover typology $(63 \%)$ than in the compartmentalized typology (43\%), $\chi^{2}(1$, $161)=6.44, p<.01$, Cramer's $V=0.20, p<.01$.

\subsubsection{Comparisons on maternal depression symptoms and children's exposure to family violence}

A significant difference between typologies was found in maternal depression symptoms, in which mothers of the spillover typology $(M=12.9, S D=5.13)$ exhibited higher levels of depression symptoms than those in the compartmentalized typology $(M=9.5, S D=5.99), t(2,160)=3.83, p<.001, d=0.71$. Children of mothers of the spillover typology $(M=10.8, S D=5.07)$ also reported a statistically significant higher exposure to family violence than in compartmentalized typology $(M=8.05$, $S D=3.82), t(2,160)=3.71, p<.001, d=0.36$.

\subsection{Typologies, externalizing problems and moderation effect}

\subsubsection{Mother-reported externalizing problems}

As presented in Table 2, the hierarchical regression model on the prediction of mother-reported children's externalizing problems 
Table 2

Moderated Hierarchical Regression Predicting Mother-reported Externalizing Problems from Typologies and Exposure to Other Forms of Family Violence.

\begin{tabular}{|c|c|c|c|c|c|c|c|c|c|c|c|c|}
\hline \multirow[t]{2}{*}{ Variable } & \multicolumn{3}{|c|}{ Step 1} & \multicolumn{3}{|c|}{ Step 2} & \multicolumn{3}{|l|}{ Step 3} & \multicolumn{3}{|c|}{ Step 4} \\
\hline & $b$ & SE & $\beta$ & $b$ & SE & $\beta$ & $b$ & SE & $\beta$ & $b$ & SE & $\beta$ \\
\hline \multicolumn{13}{|l|}{ Step 1} \\
\hline Child age & 0.16 & 0.16 & .06 & 0.15 & 0.15 & .05 & -0.02 & 0.05 & .09 & -0.02 & 0.15 & -.01 \\
\hline Child gender & 2.65 & 0.63 & $.32^{* * *}$ & 1.91 & 0.60 & $.23^{* *}$ & 1.95 & 0.58 & $.24 * * *$ & 1.97 & 0.58 & $.24^{* * * *}$ \\
\hline Maternal depression symptoms & 0.15 & 0.06 & $.21^{* *}$ & 0.09 & 0.05 & .12 & .06 & 0.05 & .09 & 0.05 & 0.05 & .07 \\
\hline \multicolumn{13}{|l|}{ Step 2} \\
\hline IPV-parenting typologies & & & & -3.06 & 0.63 & $-.37 * * *$ & -2.58 & 0.62 & $-.31 * * *$ & -2.42 & 0.62 & $-.29 * * *$ \\
\hline \multicolumn{13}{|l|}{ Step 3} \\
\hline Child's exposure to other forms of family violence & & & & & & & 0.22 & 0.07 & $.25 * * *$ & 0.13 & .08 & .14 \\
\hline \multicolumn{13}{|l|}{ Step 4} \\
\hline Typologies $\times$ Child's exposure to other forms of family violence & & & & & & & & & & -0.30 & 0.14 & $.18^{*}$ \\
\hline$R^{2}$ & .16 & & & .27 & & & .33 & & & .35 & & \\
\hline$\Delta R^{2}$ & - & & & .11 & & & .06 & & & .02 & & \\
\hline$F$ & $9.04^{*}$ & & & 13.77 & $* * *$ & & $14.08 * *$ & & & 12.84 & & \\
\hline$\Delta F$ & - & & & 23.79 & $* * *$ & & $11.42^{* *}$ & & & $4.82^{*}$ & & \\
\hline Cohen's $f^{2}$ & 0.19 & & & 0.37 & & & 0.49 & & & 0.54 & & \\
\hline
\end{tabular}

${ }^{*} p<.05 . * * p<.01 . * * * p<.001$

with IPV-parenting typologies, children's exposure to family violence and the interaction between typologies and children's exposure to violence as predictors was significant (after controlling for covariates), $F(6,156)=12.84, p<.001, f^{2}=0.54$. The final model accounted for $35 \%$ of the variance in children's externalizing problems. Inspection of the beta coefficients in Step 2 indicated that, controlling for all covariates in the model, typologies were significantly associated with SDQ externalizing problems scores, $\beta=-.37$, $p<.001$. As presented in Fig. 1, mothers in the spillover typology reported significantly more externalizing problems than mothers in the compartmentalized typology, $F(4,158)=13.77, p<.001$. In Step 4 , the explained variance in externalizing problems significantly increased with the addition of an interaction term between typologies and children's exposure to family violence $\left(\Delta R^{2}=.02, p<.05\right)$. In order to interpret these results, the interaction effect between IPV-parenting typologies and children's exposure to other forms of violence was analyzed by plotting the prediction of externalizing problems for mothers in the spillover (coded as 0 ) and in the compartmentalized (coded as 1) typologies depending on low (- $1 S D$ ) and high $(+1 S D)$ children's exposure to family violence. Results from the simple slope tests are displayed in Fig. 1. Despite the fact that both simple slopes were negative and differed significantly from zero, the association between typologies and externalizing problems was stronger among children with high exposure to other forms of family violence $(+1 S D), B=-6.70, t=-7.01, p<.001$, than in children with low exposure to other forms of family violence $(-1 S D), B=-10.94, t=-11.04, p<.001$.

\subsubsection{Teacher-reported externalizing problems}

The hierarchical regression model on the prediction of teacher-reported children's externalizing problems was tested using the reports of the 58 teachers who have returned the assessment protocol. No missing data were found in the SDQ responses among the participating teachers. As presented in Table 3, results of the hierarchical regression model (controlling for covariates entered in Step 1) indicated that IPV-parenting typologies entered in Step 2 were significantly associated with teacher-SDQ externalizing problems, $\beta$ $=-.33, p<.01$. Teachers reported higher levels of externalizing problems in children of mothers of the spillover typology than those of compartmentalized typology, $F(4,54)=3.48, p<.01$ (Fig. 1). In addition, variables entered in Step 3 (children's exposure to other forms of family violence) and in Step 4 (interaction term) did not contribute additional variance to teacher-reports of the SDQ externalizing problems, $R^{2}=.26, \Delta R^{2}=.05, n s$, and $R^{2}=.26, \Delta R^{2}=.001, n s$., respectively. The final model accounted for $26 \%$ of the variance in children's externalizing problems, $F(6,52)=2.93, p<.01, f^{2}=0.35$.

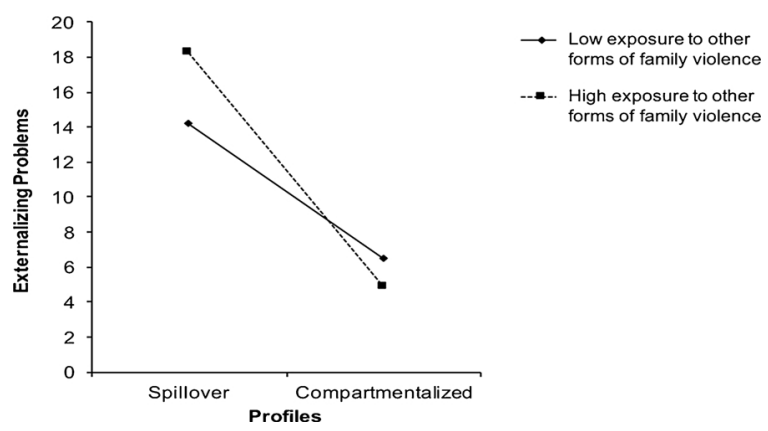

Fig. 1. Interaction between typologies and children's exposure to other forms of family violence in predicting externalizing problems. 
Table 3

Moderated Hierarchical Regression Predicting Teacher-reported Externalizing Problems from Typologies and Exposure to Other Forms of Family Violence.

\begin{tabular}{|c|c|c|c|c|c|c|c|c|c|c|c|c|}
\hline \multirow[t]{2}{*}{ Variable } & \multicolumn{3}{|l|}{ Step 1} & \multicolumn{3}{|l|}{ Step 2} & \multicolumn{3}{|l|}{ Step 3} & \multicolumn{3}{|l|}{ Step 4} \\
\hline & $b$ & SE & $\beta$ & $b$ & SE & $\beta$ & $b$ & SE & $\beta$ & $b$ & SE & $\beta$ \\
\hline \multicolumn{13}{|l|}{ Step 1} \\
\hline Child age & 0.56 & 0.35 & .21 & 0.56 & 0.33 & .21 & 0.25 & 0.37 & .09 & 0.26 & 0.38 & .10 \\
\hline Child gender & -0.32 & 1.44 & -.03 & -1.58 & 1.47 & -.14 & -1.63 & 1.44 & -.15 & -1.58 & 1.46 & -.14 \\
\hline Maternal depression symptoms & 0.28 & 0.11 & $.30 *$ & 0.26 & 0.12 & $.27^{*}$ & 0.23 & 0.12 & $.24 *$ & 0.22 & 0.12 & .23 \\
\hline \multicolumn{13}{|l|}{ Step 2} \\
\hline IPV-parenting typologies & & & & -3.72 & 1.49 & $-.33 * *$ & -3.13 & 1.50 & $-.27^{*}$ & -3.02 & 1.55 & $-.27 *$ \\
\hline \multicolumn{13}{|l|}{ Step 3} \\
\hline Child's exposure to other forms of family violence & & & & & & & 0.31 & 0.17 & .25 & 0.28 & 0.20 & .23 \\
\hline \multicolumn{13}{|l|}{ Step 4} \\
\hline Typologies $\times$ Child's exposure to other forms of family violence & & & & & & & & & & 0.11 & 0.39 & .04 \\
\hline$R^{2}$ & .12 & & & .21 & & & .26 & & & .26 & & \\
\hline$\Delta R^{2}$ & - & & & .09 & & & .05 & & & .001 & & \\
\hline$F$ & 2.34 & & & $3.48 * *$ & & & $3.56^{* *}$ & & & $2.93^{* *}$ & & \\
\hline$\Delta F$ & - & & & $6.21^{*}$ & & & 3.29 & & & 0.09 & & \\
\hline Cohen's $f^{2}$ & 0.14 & & & 0.27 & & & 0.35 & & & 0.35 & & \\
\hline
\end{tabular}

${ }^{*} p<.05 . * * p<.01 . * * * p<.001$

\section{Discussion}

Although some previous variable-centered studies have identified associations between IPV, parenting practices, and children's externalizing problems, little progress has been made in identifying typologies of IPV and parenting practices in mothers and how these typologies may be associated with children's externalizing problems. Another major limitation of the current scientific knowledge regarding the association between IPV-parenting interplay and children's externalizing problems is it was developed predominantly based on empirical research conducted with North-American samples. To our knowledge, our research was the first empirical study conducted with a non-American, high-risk, and police-reported IPV sample that examined this association. This study was designed to address three main questions. The first question was whether different typologies of IPV and maternal parenting practices derived from a person-based approach would be found in a sample of mothers with police-documented IPV. Consistent with the findings of Sturge-Apple et al. (2014), two typologies of interplay between IPV and parenting practices were identified: a cluster with high levels of sexual coercion and physical and psychological violence, coupled with high levels of harsh and inconsistent parenting, labeled as spillover typology; and a cluster with high levels of physical and sexual violence, relatively high levels of psychological violence victimization, and low levels of maternal harsh and inconsistent parenting practices, labeled as compartmentalized typology.

As expected, the typologies that emerged in the present analyses demonstrated the multiplicity of experiences within families characterized by IPV. These findings highlight that spillover and compartmentalizing parenting both exist within families whose mothers have been exposed to severe forms of IPV. In addition, when compared with former research, one major methodological advancement of the present study was the use of the cluster analytic procedure to identify typologies. This approach provided a precise account of the intersection of IPV and parenting practices variables in terms of which variables dominated the typologies. Our results showed that typologies were significantly distinct in parenting practices and similar in IPV exposure. These findings could explain such variability in parenting practices among women exposed to similar levels of IPV. We hypothesize that this variability may be associated with additional explanatory mechanisms beyond IPV exposure. As our findings showed that typologies differed in depression symptoms, it is plausible to think that depression may function as a key intraindividual factor that is directly associated with variability in parenting practices in families with IPV. The plausibility of this supposition finds support in previous research that has suggested that parenting might be particularly impaired by maternal depression symptoms (Callender et al., 2012). The potential explanatory value of depression symptoms in interindividual differences in parenting practices finds further support in previous theoretical proposals. Action-control models of parental self-regulation posit that depression symptoms impair cognitive and affective self-regulatory mechanisms (Dix \& Meunier, 2009). In particular, depression symptoms are linked to lower child-oriented goals, lower perceived parenting competence, engagement in low-effort and short-term goals in family interactions, and higher negative appraisals of children (Callender et al., 2012; Lovejoy et al., 2000). These impairments subsequently activate motivational-cognitive biases, negative emotional arousal, and dysregulation that ultimately increase mothers' predisposition to use more ineffective and disruptive behavioral strategies to manage parenting demands (Crick \& Dodge, 1994; Haskett et al., 2003).

In addition, depression-related impairments in mothers' self-regulation may also weaken their competence in modulating negative emotional arousal and dysregulation in mother-child interactions. Conceptual frameworks advocate anger as a primary emotional reaction to physical and affective pain (Bruehl et al., 2006). These anger arousals, associated with hostile distortions and high sensibility to aversive stimulation found in depressed individuals (Dix et al., 2014; Smith et al., 2016), may predispose depressed mothers exposed to IPV to even greater levels of dysregulated behavioral anger expression in parenting interactions (Callender et al., 2012; Du Rocher Schudlich \& Cummings, 2007; Lamela \& Figueiredo, 2013).This potential interplay between IPV, parenting, 
depression symptoms, anger, and pain should be examined in future research. Forthcoming work should also test other sources of interindividual variability in parenting practices beyond current exposure to IPV, such as adversity history, attachment, self-regulatory systems, and neurobiological functioning.

An unexpected finding was the significant higher proportion of boys in the spillover typology than in the compartmentalized typology. Although caution in interpreting this finding is warranted, two empirical-based hypotheses for this result might be speculated. First, mothers' gender role stereotypes in children's socialization might contribute to the use of harsher parenting practices in boys than in girls (e.g., Endendijk et al., 2016). Some scholars have suggested that parents tend to reveal more positive attitudes toward the corporal punishment with boys to modulate and control their behavior (McKee et al., 2007). Therefore, based on this gender role stereotype hypothesis, it might be expected a higher proportion of boys in spillover typology which is characterized by greater maternal coercive parenting strategies to force children to comply. Second, the higher proportion of boys in the spillover typology might also be explained by maternal and child difficulties in self-regulation processes. Research has indicated mothers' selfregulation skills as a key mechanism to foster children's acquisition of behavioral, emotional, and cognitive self-regulation skills in both low-risk and IPV samples (Bridgett et al., 2015; Katz et al., 2016). Previous empirical work has also documented bidirectional associations between mothers' depression symptoms and self-regulation difficulties that in turn are associated to the use of more coercive and inconsistent parenting strategies (Kohlhoff et al., 2016). As mothers in spillover typology showed higher levels of depression, it is possible to speculate that these mothers present higher difficulties of self-regulation than mothers in compartmentalized typology. These difficulties in maternal self-regulation may exert a differential effect on self-regulation difficulties by children's gender. As boys tend to have lower levels of self-regulation than girls (Montroy et al., 2016) and they also need more external efforts to acquire self-regulation skills than girls (Mileva-Seitz et al., 2015), problems in maternal self-regulation might have a higher detrimental effect on boys' self-regulation skills. As a result, heightned level of boys' self-regulation difficulties may impel mothers to apply more ineffective parenting practices (e.g., corporal punishment) to control boys' behavioral and emotional dysregulated responses (Sulik et al., 2015), increasing, therefore, the proportion of boys in the spillover typology. However, as this association between ineffective parenting practices and children's gender is not entirely consistent in the literature, future research should replicate this finding and, in case of replication, these two potential mechanisms should be examined.

By replicating IPV-typologies found in the Sturge-Apple's et al. (2014) study with an American community sample, our findings also extend the literature by demonstrating that these typologies might be stable across different cultural settings as well as to distinct levels of IPV severity. More specifically, our study highlights the presence of effective parenting practices among women exposed to police-reported IPV, which are described in literature as more likely to have been exposed to more severe events of IPV when compared with women with no history of police-reported IPV (Akers \& Kaukinen, 2009; Sanz-Barbero et al., 2016). By detecting both spillover and compartmentalizing patterns in high-risk police-reported IPV sample, our results illuminate about the substantial heterogeneity of parenting practices among women exposed to IPV, contrasting with prior variable-centered research that has only found empirical evidence for spillover dynamics (e.g., Greene et al., 2018; Holmes, 2013). Thus, this study not only demonstrates the importance of person-centered approaches to detect such population heterogeneity in the interplay between IPV-parenting but also reveals that a group of mothers exposed to potentially more severe forms of IPV may still be able to parent effectively. This is particularly relevant since disturbances in parenting practices could be expected in mothers exposed to severe or multiple forms of IPV in accordance with some cumulative risk models. In particular, the cumulative stressors model postulates that under a certain level of stress severity, positive functioning may not be possible, even for those individuals who show significant competencies and strengths (Jaffee et al., 2007). Accordingly, it would be possible that a compartmentalizing pattern could not be present in the population of mothers with police-reported IPV since they were presumably exposed to more severe and/or multiple forms of IPV, and thus jeopardizing their positive functioning in parenting. In contrast with this hypothesis, our findings extend the Sturge-Apple's et al. (2014) study by suggesting the similarity of compartmentalizing and spillover processes in mothers across different levels of IPV severity.

The second aim of this study was to examine whether IPV-parenting typologies would be associated with children's externalizing problems, as reported by mothers and teachers. We found that typologies were significantly associated with externalizing symptoms in both regression models. Findings were strongest for mother-reported externalizing problems. Our results showed that externalizing symptoms were significantly lower in children of mothers classified in the compartmentalized group compared to those in the spillover group. This finding contributes to the elucidation of the inconclusive pattern of findings of previous literature (Easterbrooks et al., 2018; Fong et al., 2017; Sturge-Apple et al., 2014).

Extending previous knowledge, our results highlight that the co-occurrence of high levels of IPV and ineffective parenting practices in the spillover group may operate cumulatively to increasing levels of externalizing problems. Previous results had already suggested that exposure to IPV increases children's emotional overreactivity that is ultimately linked with externalizing problems (Fong et al., 2017; Ingoldsby et al., 1999). According to the emotional security theory, repeated exposure to interparental conflict characterized by hostility, anger, or injury increases children's vulnerability to adjustment problems by undermining their sense of emotional security in the family as a reliable environment to fulfill their instrumental and emotional needs (Davies \& Martin, 2014). As a result, emotional overreactivity is thought to be a coping strategy with which to face highly unpredictable and conflicted family environments.

However, our findings bring to light that children exposed to IPV and ineffective parenting (spillover typology) are those that exhibit higher mean levels of externalizing problems, when compared to those exposed to IPV but whose mothers exhibit lower levels of ineffective parenting (compartmentalized typology). Although caution in interpretation is warranted, we hypothesize that this novel finding might explain the synergistic influence that IPV and harsh parenting practices exert over children's emotional experiences in the family environment. Consistent with the cumulative risk hypothesis (Evans et al., 2013), we suggest that the high 
rates of externalizing problems in the spillover typology may be associated with the accumulated exposure to multiple interpersonal relationships characterized by anger and emotional dysregulation. As emotional reactivity to interpersonal conflict is thought by social learning frameworks as the main mechanism for the intergenerational transmission of anger-based strategies within families, the synchronic presence of anger-based strategies in different family subsystems may cumulatively trigger even greater levels of dysregulation in children's emotional and neurobiological systems and subsequent externalizing difficulties. This assumption is particularly plausible since both IPV and harsh parenting are associated in adults with anger dysregulation, higher irritability, a lower threshold to frustration, and lower empathic responding, suggesting that these interpersonal strategies may share similar emotional underpinnings.

Simultaneously, spillover functioning may jeopardize parents' ability to do emotional socialization of their children, which is linked with children's lower emotional skills and future externalizing problems (Eisenberg et al., 1998). For example, a recent metaanalytic study found that nonsupportive parental emotion socialization behaviors (e.g., avoidance of emotional discussion, minimizing or punitive reactions to children's emotions, and dysregulated emotional expressiveness within the family) were significantly associated with severity of concurrent externalizing problems (Johnson et al., 2017). Such associations were greater during early childhood when the children are developing the capacity of emotional self-regulation and emotional awareness, and when children's identification with their parents achieves the highest point (Sternberg et al., 2006).

The results of the present study also suggest that parenting practices are not operating as a protective family factor of IPV in the spillover group. This finding is in agreement with former research that tested the protective effect of parenting dimensions in the relationship between IPV and children's externalizing problems (Easterbrooks et al., 2018; Manning et al., 2014; Skopp et al., 2007). For example, Easterbrooks et al. (2018) found that IPV did not differentially affect externalizing problems in children of mothers with low harsh parenting practices. A longitudinal study with American mothers also showed that maternal sensitivity had a protective effect on the association between IPV and children's angry reactivity to interparental conflict, which is a developmental antecedent for externalizing problems (Manning et al., 2014). Specifically, that study showed that IPV predicted subsequent increases in child externalizing problems over a 2-year period only for children experiencing low levels of maternal sensitivity. Based on our results and those previous empirical findings, future work should examine the interplay between IPV and ineffective and positive parenting practices.

Finally, we tested whether the direct exposure to other forms of family violence would moderate the association between IPVparenting typologies and children's externalizing problems. Our findings revealed that the change in externalizing problems was greater for children with high exposure to other forms family violence than those with low levels of exposure to other forms of family violence. Specifically, children with high exposure to other forms of family violence showed the highest levels of externalizing problems when mothers were classified into the spillover typology, but they exhibited the lowest levels of externalizing problems when mothers were classified in the compartmentalized typology.

These intriguing results suggest that the compartmentalized functioning may have a protective effect in children's psychological adjustment, even for those children with high direct exposure to other forms of family violence. These findings suggest that the parenting of mothers of the compartmentalized typology may not protect their children from exposure to IPV and other forms of family violence, but it may partially help children cope with the effects of exposure to different forms of violence inside the family. Consistent with the cognitive-contextual framework of family violence and children's adjustment, more effective parenting practices may positively shape children's appraisals and emotional response to the conflict by, for example, reducing perceived threat, increasing children's coping efficacy, and modulating emotion expressiveness. Effective parenting practices, even for those children with additional high exposure to other forms of family violence, may also operate as a secure base, providing a higher sense of emotional security within the family (Bernier et al., 2015; Cummings et al., 2015; Mazefsky \& Farrell, 2005). For example, one study found that parenting and family support moderated the association between witnessing violence and aggressive behavior, such that this relationship was stronger among adolescents who reported low family support, high levels of inconsistent parenting, or low parental monitoring (Mazefsky \& Farrell, 2005).

In contrast, the highest levels of externalizing problems reported by children with high exposure to other forms of family violence in the spillover group are consistent with the evolutionary-developmental assumptions of adaptative development (Ellis et al., 2011). According to this framework, anger and oppositional behaviors displayed by children are developmental adaptations to a harsh family environment that allow them to alleviate the costs of such conditions. Similarly, by showing differential levels of externalizing problems in the function of different levels of exposure to other forms of family violence, our results suggest that children may react differently depending on the family environment. Thus, although our study was not designed to examine children's differential susceptibility to IPV-parenting typologies and other forms of family violence, our results, nevertheless, open this line of inquiry.

Some limitations must be considered when interpreting the results of this research. First, despite self-reported measures of parenting used in the current study having shown significant associations with interviewing and observational measures (Arnold et al., 1993), multi-informant and multimethod procedures to assess parenting could have contributed to a decreased possible shared method variance and also a higher accuracy of measurement. Second, our theoretically-based hypotheses were tested using correlational data, and no strong causal effects could be concluded. In particular, changes in IPV exposure, parenting practices, and the severity of depression symptoms over time might be expected. However, due to the cross-sectional design of the current study, the potential differential impact of these changes over time on children's externalizing problems was not tested. Finally, the regression models tested in the current research did not include mothers' emotional regulation strategies, or children's appraisals and emotional reactivity to conflict, which might have contributed to a more extensive portrait of the associations between IPV-parenting typologies and children's externalizing problems.

In summary, our results suggest that a typological approach might be more useful in understanding key combinations of IPV- 
parenting practices that children are exposed to, as well as in establishing which of those combinations are most significantly associated with children's externalizing problems. The characteristics of these risk typologies, along with their differential expected rates of externalizing symptoms at different levels of exposure to other forms of family violence, may inform preventive and clinical interventions.

\section{Appendix A. Supplementary data}

Supplementary material related to this article can be found, in the online version, at doi:https://doi.org/10.1016/j.chiabu.2018. 04.020.

\section{References}

Aiken, L., West, S., \& Reno, R. (1991). Multiple regression: Testing and interpreting interactions. Newbury Park, CA: Sage Publications.

Akers, C., \& Kaukinen, C. (2009). The police reporting behavior of intimate partner violence victims. Journal of Family Violence, 24, 159-171. http://dx.doi.org/10. 1007/s10896-008-9213-4.

Alves, M., Manita, C., Caldas, I., Fernández-Martinez, E., Gomes da Silva, A., \& Magalhães, T. (2016). Evolution and analysis of cultural and cognitive factors related with domestic violence against women. Journal of Interpersonal Violence. http://dx.doi.org/10.1177/0886260516645570 Advance online publication.

Arnold, D., O'Leary, S., Wolff, L., \& Acker, M. (1993). The parenting scale: A measure of dysfunctional parenting in discipline situations. Psychological Assessment, 5, 137-144. http://dx.doi.org/10.1037/1040-3590.5.2.137.

Bauer, N. S., Gilbert, A. L., Carroll, A. E., \& Downs, S. M. (2013). Associations of early exposure to intimate partner violence and parental depression with subsequent mental health outcomes. JAMA Pediatrics, 167, 341. http://dx.doi.org/10.1001/jamapediatrics.2013.780.

Belsky, J., \& Fearon, R. M. P. (2004). Exploring marriage-parenting typologies and their contextual antecedents and developmental sequelae. Development and Psychopathology, 16, 501-523. http://dx.doi.org/10.1017/S095457940400464X.

Bergman, L. R., \& Andersson, H. (2010). The person and the variable in developmental psychology. Zeitschrift Für Psychologie / Journal of Psychology, 218, 155-165. http://dx.doi.org/10.1027/0044-3409/a000025.

Bernier, A., Beauchamp, M. H., Carlson, S. M., \& Lalonde, G. (2015). A secure base from which to regulate: Attachment security in toddlerhood as a predictor of executive functioning at school entry. Developmental Psychology, 51, 1177-1189. http://dx.doi.org/10.1037/dev0000032.

Bridgett, D., Burt, N., Edwards, E., \& Deater-Deckard, K. (2015). Intergenerational transmission of self-regulation: A multidisciplinary review and integrative conceptual framework. Psychological Bulletin, 141, 602-654. http://dx.doi.org/10.1037/a0038662.

Bruehl, S., Chung, O. Y., \& Burns, J. W. (2006). Anger expression and pain: An overview of findings and possible mechanisms. Journal of Behavioral Medicine, 29, 593-606. http://dx.doi.org/10.1007/s10865-006-9060-9.

Callender, K. A., Olson, S. L., Choe, D. E., \& Sameroff, A. J. (2012). The effects of parental depressive symptoms, appraisals, and physical punishment on later child externalizing behavior. Journal of Abnormal Child Psychology, 40, 471-483. http://dx.doi.org/10.1007/s10802-011-9572-9.

Campbell, A., Hicks, R., Thompson, S., \& Wiehe, S. (2017). Characteristics of intimate partner violence incidents and the environments in which they occur: Victim reports to responding law enforcement officers. Journal of Interpersonal Violence. http://dx.doi.org/10.1177/0886260517704230 Advance online publication.

Canavarro, C. (1999). Inventário de sintomas psicopatológicos: BSI [The brief symptoms inventory: BSI]. In M. Simões, M. Gonçalves, \& L. Almeida (Eds.). Testes e provas psicológicas em Portugal [psychological tests in Portugal] (pp. 95-109). APPORT: Braga, Portugal.

Capaldi, D. M., Knoble, N. B., Shortt, J. W., \& Kim, H. K. (2012). A systematic review of risk factors for intimate partner violence. Partner Abuse, 3, 231-280. http://dx. doi.org/10.1891/1946-6560.3.2.231.

Casanueva, C., Martin, S. L., Runyan, D. K., Barth, R. P., \& Bradley, R. H. (2008). Quality of maternal parenting among intimate-partner violence victims involved with the child welfare system. Journal of Family Violence, 23, 413-427. http://dx.doi.org/10.1007/s10896-008-9167-6.

Costa, D., Soares, J., Lindert, J., Hatzidimitriadou, E., Sundin, Ö., Toth, O., ... Barros, H. (2015). Intimate partner violence: A study in men and women from six European countries. International Journal of Public Health, 60, 467-478. http://dx.doi.org/10.1007/s00038-015-0663-1.

Crick, N. R., \& Dodge, K. A. (1994). A review and reformulation of social information-processing mechanisms in children's social adjustment. Psychological Bulletin, 115, 74-101. http://dx.doi.org/10.1037/0033-2909.115.1.74.

Cruz, O., Raposo, J. V., Ducharne, M. A. B., Silva Almeida, L. D.a., Teixeira, C. M., \& Fernandes, H. M. (2011). Questionário de estilos educativos parentais (QEEP): Contributos para a validação factorial da versão portuguesa das parenting scales. Revista Iberoamericana Diagnostico y Evaluacion Psicologica, 1, 157-176.

Cummings, E. M., Koss, K. J., \& Davies, P. T. (2015). Prospective relations between family conflict and adolescent maladjustment: Security in the family system as a mediating process. Journal of Abnormal Child Psychology, 43, 503-515. http://dx.doi.org/10.1007/s10802-014-9926-1.

Davies, P., \& Martin, M. (2014). Children's coping and adjustment in high-conflict homes: The reformulation of emotional security theory. Child Development Perspectives, 8, 242-249. http://dx.doi.org/10.1111/cdep.12094.

Dawson, J. F., \& Richter, A. W. (2006). Probing three-way interactions in moderated multiple regression: Development and application of a slope difference test. Journal of Applied Psychology, 91, 917-926. http://dx.doi.org/10.1037/0021-9010.91.4.917.

Derogatis, L. R., \& Melisaratos, N. (1983). The brief symptom inventory: An introductory report. Psychological Medicine, 13, 595-605. http://dx.doi.org/10.1017/ S0033291700048017.

Dix, T., \& Meunier, L. N. (2009). Depressive symptoms and parenting competence: An analysis of 13 regulatory processes. Developmental Review, 29, 45-68. http://dx. doi.org/10.1016/j.dr.2008.11.002.

Dix, T., Moed, A., \& Anderson, E. R. (2014). Mothers' depressive symptoms predict both increased and reduced negative reactivity: Aversion sensitivity and the regulation of emotion. Psychological Science, 25, 1353-1361. http://dx.doi.org/10.1177/0956797614531025.

Du Rocher Schudlich, T. D., \& Cummings, E. M. (2007). Parental dysphoria and children's adjustment: Marital conflict styles, children's emotional security, and parenting as mediators of risk. Journal of Abnormal Child Psychology, 35, 627-639. http://dx.doi.org/10.1007/s10802-007-9118-3.

Easterbrooks, M., Katz, R., Kotake, C., Stelmach, N., \& Chaudhuri, J. (2018). Intimate partner violence in the first 2 years of life: Implications for toddlers' behavior regulation. Journal of Interpersonal Violence, 33, 1192-1214. http://dx.doi.org/10.1177/0886260515614562.

Ehrensaft, M. K., Knous-Westfall, H., \& Cohen, P. (2017). Long-term influence of intimate partner violence and parenting practices on offspring trauma symptoms. Psychology of Violence, 7, 296-305. http://dx.doi.org/10.1037/a0040168.

Eisenberg, N., Cumberland, A., \& Spinrad, T. L. (1998). Parental socialization of emotion. Psychological Inquiry, 9, 241-273. http://dx.doi.org/10.1207/ s15327965pli0904_1.

Ellis, B. J., Boyce, W. T., Belsky, J., Bakermans-Kranenburg, M. J., \& van Ijzendoorn, M. H. (2011). Differential susceptibility to the environment: An evolutionary-neurodevelopmental theory. Development and Psychopathology, 23, 7-28. http://dx.doi.org/10.1017/S0954579410000611.

Endendijk, J., Groeneveld, M., Bakermans-Kranenburg, M., \& Mesman, J. (2016). Gender-differentiated parenting revisited: Meta-analysis reveals very few differences in parental control of boys and girls. PLOS ONE, 11, e0159193. http://dx.doi.org/10.1371/journal.pone.0159193.

Erel, O., \& Burman, B. (1995). Interrelatedness of marital relations and parent-child relations: A meta-analytic review. Psychological Bulletin, 118, 108-132. http://dx. doi.org/10.1037/0033-2909.118.1.108.

Eurobarometer, \& European Comission (2010). Domestic violence against women (Special eurobarometer). Brussels: Directorate-General for Communication of the European Union.

European Union Agency for Fundamental Rights (2014). Violence against women: An EU-wide survey - Main results reportLuxembourg: Publications Office of the 
European Union.

Evans, G. W., Li, D., \& Whipple, S. S. (2013). Cumulative risk and child development. Psychological Bulletin, 139, 1342-1396. http://dx.doi.org/10.1037/a0031808.

Finkelhor, D., Turner, H., Shattuck, A., \& Hamby, S. (2015). Prevalence of childhood exposure to violence, crime, and abuse. JAMA Pediatrics, 169, 746-754. http://dx. doi.org/10.1001/jamapediatrics.2015.0676.

Fong, V. C., Hawes, D., \& Allen, J. L. (2017). A systematic review of risk and protective factors for externalizing problems in children exposed to intimate partner violence. Trauma, Violence, \& Abuse. http://dx.doi.org/10.1177/1524838017692383 Advance online publication.

Fox, N., \& Leavitt, L. (1996). Violence exposure scale for children-revised. Philadephia: University of Pennsylvania.

Frazier, P. A., Tix, A. P., \& Barron, K. E. (2004). Testing moderator and mediator effects in counseling psychology research. Journal of Counseling Psychology, 51, 115-134. http://dx.doi.org/10.1037/0022-0167.51.1.115.

Gilbert, A. L., Bauer, N. S., Carroll, A. E., \& Downs, S. M. (2013). Child exposure to parental violence and psychological distress associated with delayed milestones. Pediatrics, 132, 1577-1583. http://dx.doi.org/10.1542/peds.2013-1020.

Goodman, A., Lamping, D. L., \& Ploubidis, G. B. (2010). When to use broader internalising and externalising subscales instead of the hypothesised five subscales on the strengths and difficulties questionnaire (SDQ): Data from british parents, teachers and children. Journal of Abnormal Child Psychology, 38, 1179-1191. http://dx. doi.org/10.1007/s10802-010-9434-x.

Goodman, R. (1997). The strengths and difficulties questionnaire: A research note. Journal of Child Psychology and Psychiatry, 38, 581-586. http://dx.doi.org/10.1111/ j.1469-7610.1997.tb01545.x.

Gracia, E., \& Herrero, J. (2008). Is it considered violence? The acceptability of physical punishment of children in Europe. Journal of Marriage and Family, 70, 210-217. http://dx.doi.org/10.1111/j.1741-3737.2007.00472.x.

Graham-Bermann, S. A., Gruber, G., Howell, K. H., \& Girz, L. (2009). Factors discriminating among profiles of resilience and psychopathology in children exposed to intimate partner violence (IPV). Child Abuse \& Neglect, 33, 648-660. http://dx.doi.org/10.1016/j.chiabu.2009.01.002.

Grasso, D. J., Henry, D., Kestler, J., Nieto, R., Wakschlag, L. S., \& Briggs-Gowan, M. J. (2016). Harsh parenting as a potential mediator of the association between intimate partner violence and child disruptive behavior in families with young children. Journal of Interpersonal Violence, 31, 2102-2126. http://dx.doi.org/10. $1177 / 0886260515572472$.

Greene, C., Chan, G., McCarthy, K., Wakschlag, L., \& Briggs-Gowan, M. (2018). Psychological and physical intimate partner violence and young children's mental health: The role of maternal posttraumatic stress symptoms and parenting behaviors. Child Abuse \& Neglect, 77, 168-179. http://dx.doi.org/10.1016/J.CHIABU. 2018.01.012.

Guerra, L., Robles, V., Bielza, C., \& Larrañaga, P. (2012). A comparison of clustering quality indices using outliers and noise. Intelligent Data Analysis, 16, 703-715. http://dx.doi.org/10.3233/IDA-2012-0545.

Hamby, S., Finkelhor, D., Turner, H., \& Ormrod, R. (2010). The overlap of witnessing partner violence with child maltreatment and other victimizations in a nationally representative survey of youth. Child Abuse \& Neglect, 34, 734-741. http://dx.doi.org/10.1016/J.CHIABU.2010.03.001.

Haskett, M. E., Smith Scott, S., Grant, R., Ward, C. S., \& Robinson, C. (2003). Child-related cognitions and affective functioning of physically abusive and comparison parents. Child Abuse \& Neglect, 27, 663-686. http://dx.doi.org/10.1016/S0145-2134(03)00103-0.

Hoeve, M., Blokland, A., Dubas, J. S., Loeber, R., Gerris, J. R. M., \& Van Der Laan, P. H. (2008). Trajectories of delinquency and parenting styles. Journal of Abnormal Child Psychology, 36, 223-235. http://dx.doi.org/10.1007/s10802-007-9172-x.

Holmes, M. (2013). Aggressive behavior of children exposed to intimate partner violence: An examination of maternal mental health, maternal warmth and child maltreatment. Child Abuse \& Neglect, 37, 520-530. http://dx.doi.org/10.1016/J.CHIABU.2012.12.006.

Houltberg, B. J., Henry, C. S., \& Morris, A. S. (2012). Family interactions, exposure to violence, and emotion regulation: Perceptions of children and early adolescents at risk. Family Relations, 61, 283-296. http://dx.doi.org/10.1111/j.1741-3729.2011.00699.x.

Ingoldsby, E. M., Shaw, D. S., Owens, E. B., \& Winslow, E. B. (1999). A longitudinal study of interparental conflict, emotional and behavioral reactivity, and preschoolers' adjustment problems among low-income families. Journal of Abnormal Child Psychology, 27, 343-356. http://dx.doi.org/10.1023/A:1021971700656.

Jaffee, S., Caspi, A., Moffitt, T., Polo-Tomás, M., \& Taylor, A. (2007). Individual, family, and neighborhood factors distinguish resilient from non-resilient maltreated children: A cumulative stressors model. Child Abuse and Neglect, 31, 231-253. http://dx.doi.org/10.1016/j.chiabu.2006.03.011.

Johnson, A. M., Hawes, D. J., Eisenberg, N., Kohlhoff, J., \& Dudeney, J. (2017). Emotion socialization and child conduct problems: A comprehensive review and metaanalysis. Clinical Psychology Review, 54, 65-80. http://dx.doi.org/10.1016/j.cpr.2017.04.001.

Jouriles, E. N., McDonald, R., Vu, N. L., \& Sargent, K. S. (2016). Children's exposure to intimate partner violence: Should sexual coercion be considered? Journal of Family Psychology, 30, 503-508. http://dx.doi.org/10.1037/fam0000146.

Jouriles, E. N., Rosenfield, D., McDonald, R., Vu, N. L., Rancher, C., \& Mueller, V. (2016). Children exposed to intimate partner violence: Conduct problems, interventions, and partner contact with the child. Journal of Clinical Child \& Adolescent Psychology. http://dx.doi.org/10.1080/15374416.2016.1163706 Advance online publication.

Katz, L., Stettler, N., \& Gurtovenko, K. (2016). Traumatic stress symptoms in children exposed to intimate partner violence: The role of parent emotion socialization and children's emotion regulation abilities. Social Development, 25, 47-65. http://dx.doi.org/10.1111/sode.12151.

Kerig, P. K., \& Swanson, J. A. (2010). Ties that bind: Triangulation, boundary dissolution, and the effects of interparental conflict on child development. In M. Schulz, M. Pruett, P. Kerig, \& R. Parke (Eds.). Strengthening couple relationships for optimal child development: Lessons from research and intervention. (pp. 59-76). Washington: American Psychological Association. http://dx.doi.org/10.1037/12058-005.

Kohlhoff, J., Hawes, D., Mence, M., Russell, A., Wedgwood, L., \& Morgan, S. (2016). Emotion regulation strategies and parenting practices among parents of children with clinic-referred conduct problems. Parenting: Science and Practice, 16, 302-319. http://dx.doi.org/10.1080/15295192.2016.1184942.

Krishnakumar, A., \& Buehler, C. (2000). Interparental conflict and parenting behaviors: A meta-analytic review. Family Relations, 49, 25-44. http://dx.doi.org/10. 1111/j.1741-3729.2000.00025.x.

Lamela, D., \& Figueiredo, B. (2018). A cumulative risk model of child physical maltreatment potential: Findings from a community-based study. Journal of Interpersonal Violence, 33, 1287-1305. http://dx.doi.org/10.1177/0886260515615142.

Lamela, D., \& Figueiredo, B. (2013). Parents' physical victimization in childhood and current risk of child maltreatment: The mediator role of psychosomatic symptoms. Journal of Psychosomatic Research, 75, 178-183. http://dx.doi.org/10.1016/j.jpsychores.2013.04.001.

Lamela, D., Figueiredo, B., Bastos, A., \& Feinberg, M. (2016). Typologies of post-divorce coparenting and parental well-being, parenting quality and children's psychological adjustment. Child Psychiatry \& Human Development, 47, 716-728. http://dx.doi.org/10.1007/s10578-015-0604-5.

Levendosky, A. A., Huth-Bocks, A. C., Shapiro, D. L., \& Semel, M. A. (2003). The impact of domestic violence on the maternal-child relationship and preschool-age children's functioning. Journal of Family Psychology, 17, 275-287. http://dx.doi.org/10.1037/0893-3200.17.3.275.

Levendosky, A. A., Leahy, K. L., Bogat, G. A., Davidson, W. S., \& von Eye, A. (2006). Domestic violence, maternal parenting, maternal mental health, and infant externalizing behavior. Journal of Family Psychology, 20, 544-552. http://dx.doi.org/10.1037/0893-3200.20.4.544.

Lovejoy, M. C., Graczyk, P. A., O’Hare, E., \& Neuman, G. (2000). Maternal depression and parenting behavior: A meta-analytic review. Clinical Psychology Review, 20, 561-592. http://dx.doi.org/10.1016/S0272-7358(98)00100-7.

Machado, C., Gonçalves, M., Matos, M., \& Dias, A. R. (2007). Child and partner abuse: Self-reported prevalence and attitudes in the north of Portugal. Child Abuse and Neglect, 31, 657-670. http://dx.doi.org/10.1016/j.chiabu.2006.11.002.

Mandara, J. (2003). The typological approach in child and family psychology: A review of theory, methods, and research. Clinical Child and Family Psychology Review, 6, 129-146. http://dx.doi.org/10.1023/A:1023734627624.

Manning, L. G., Davies, P. T., \& Cicchetti, D. (2014). Interparental violence and childhood adjustment: How and why maternal sensitivity is a protective factor. Child Development, 85, 2263-2278. http://dx.doi.org/10.1111/cdev.12279.

Marzocchi, G. M., Capron, C., Di Pietro, M., Duran Tauleria, E., Duyme, M., Frigerio, A., ... Thérond, C. (2004). The use of the strengths and difficulties questionnaire (SDQ) in Southern European countries. European Child \& Adolescent Psychiatry, 13(S2), ii40-ii46. http://dx.doi.org/10.1007/s00787-004-2007-1.

Masyn, K. (2013). Latent class analysis and finite mixture modeling. In T. Little (Vol. Ed.), The Oxford handbook of quantitative methods in psychology: Vol 2, (pp. 551- 
611). New York, NY: Oxford University Press.

Mazefsky, C. A., \& Farrell, A. D. (2005). The role of witnessing violence, peer provocation, family support, and parenting practices in the aggressive behavior of rural adolescents. Journal of Child and Family Studies, 14, 71-85. http://dx.doi.org/10.1007/s10826-005-1115-y.

McFarlane, J. M., Groff, J. Y., O’Brien, J. A., \& Watson, K. (2003). Behaviors of children who are exposed and not exposed to intimate partner violence: An analysis of 330 black, white, and hispanic children. Pediatrics, 112, 202-207. http://dx.doi.org/10.1542/peds.112.3.e202.

McKee, L., Roland, E., Coffelt, N., Olson, A., Forehand, R., Massari, C., ... Zens, M. (2007). Harsh discipline and child problem behaviors: The roles of positive parenting and gender. Journal of Family Violence, 22, 187-196. http://dx.doi.org/10.1007/s10896-007-9070-6.

Mileva-Seitz, V., Ghassabian, A., Bakermans-Kranenburg, M., van den Brink, J., Linting, M., Jaddoe, V., ... van IJzendoorn, M. (2015). Are boys more sensitive to sensitivity? Parenting and executive function in preschoolers. Journal of Experimental Child Psychology, 130, 193-208. http://dx.doi.org/10.1016/J.JECP.2014.08. 008.

Miller, L., Grabell, A., Thomas, A., Bermann, E., \& Graham-Bermann, S. (2012). The associations between community violence, television violence, intimate partner violence, parent-child aggression, and aggression in sibling relationships of a sample of preschoolers. Psychology of Violence, 2, 165-178. http://dx.doi.org/10. $1037 / \mathrm{a} 0027254$.

Miller, L. S., Wasserman, G. A., Neugebauer, R., Gorman-Smith, D., \& Kamboukos, D. (1999). Witnessed community violence and antisocial behavior in high-risk, urban boys. Journal of Clinical Child Psychology, 28, 2-11. http://dx.doi.org/10.1207/s15374424jccp2801_1.

Milligan, G. W., \& Cooper, M. C. (1985). An examination of procedures for determining the number of clusters in a data set. Psychometrika, 50, 159-179. http://dx.doi. org/10.1007/BF02294245.

Montroy, J., Bowles, R., Skibbe, L., McClelland, M., \& Morrison, F. (2016). The development of self-regulation across early childhood. Developmental Psychology, 52, 1744-1762. http://dx.doi.org/10.1037/dev0000159.

Paiva, C., \& Figueiredo, B. (2006). Versão portuguesa das "Escalas de Táticas de Conflito Revisadas": Estudo de validação [The Portuguese version of "Revised conflict tactics scales": Validation study]. Psicologia Teoria e Prática, 8(2), 14-39.

Rupp, A. (2013). Clustering and classification. In T. Little (Ed.). The Oxford handbook of quantitative methods (pp. 517-550). Oxford University Press: New York.

Sanz-Barbero, B., Otero-García, L., \& Vives-Cases, C. (2016). Factors associated with women's reporting of intimate partner violence in Spain. Journal of Interpersonal Violence. http://dx.doi.org/10.1177/0886260515625512 Advance online publication.

Skopp, N., McDonald, R., Jouriles, E. N., \& Rosenfield, D. (2007). Partner aggression and children's externalizing problems: Maternal and partner warmth as protective factors. Journal of Family Psychology, 21, 459-467. http://dx.doi.org/10.1037/0893-3200.21.3.459.

Smith, S., Chen, J., Basile, K., Gilbert, L., Merrick, M., Patel, N., ... Jain, A. (2017). The national intimate partner and sexual violence survey (NISVS): 2010-2012 State reportAtlanta, GA..

Smith, H., Summers, B., Dillon, K., Macatee, R., \& Cougle, J. (2016). Hostile interpretation bias in depression. Journal of Affective Disorders, 203, 9-13. http://dx.doi. org/10.1016/j.jad.2016.05.070.

Sousa, B. (2015). Adaptação e validação da escala de exposição à violência em crianças (VEX-R) para a população portuguesa [adaptation and validation of the Portuguese version of the violence exposure scale for children]. Lusófona University of Porto.

Sternberg, K. J., Baradaran, L. P., Abbott, C. B., Lamb, M. E., \& Guterman, E. (2006). Type of violence, age, and gender differences in the effects of family violence on children's behavior problems: A mega-analysis. Developmental Review, 26, 89-112. http://dx.doi.org/10.1016/j.dr.2005.12.001.

Straus, M. A., Hamby, S. L., Boney-McCoy, S., \& Sugarman, D. B. (1996). The revised conflict tactics scales (CTS2). Journal of Family Issues, 17, 283-316. http://dx.doi. org/10.1177/019251396017003001.

Sturge-Apple, M. L., Davies, P. T., Cicchetti, D., \& Fittoria, M. G. (2014). A typology of interpartner conflict and maternal parenting practices in high-risk families: Examining spillover and compensatory models and implications for child adjustment. Development and Psychopathology, 26, 983-998. http://dx.doi.org/10.1017/ S0954579414000509.

Sulik, M., Blair, C., Mills-Koonce, R., Berry, D., \& Greenberg, M. (2015). Early parenting and the development of externalizing behavior problems: Longitudinal mediation through children's executive function. Child Development, 86, 1588-1603. http://dx.doi.org/10.1111/cdev.12386.

von Eye, A., \& Bergman, L. R. (2003). Research strategies in developmental psychopathology: Dimensional identity and the person-oriented approach. Development and Psychopathology, 15, 553-580. http://dx.doi.org/10.1017/S0954579403000294.

Vu, N. L., Jouriles, E. N., McDonald, R., \& Rosenfield, D. (2016). Children's exposure to intimate partner violence: A meta-analysis of longitudinal associations with child adjustment problems. Clinical Psychology Review, 46, 25-33. http://dx.doi.org/10.1016/j.cpr.2016.04.003.

Zilcha-Mano, S., McCarthy, K. S., Dinger, U., Chambless, D. L., Milrod, B. L., Kunik, L., ... Barber, J. P. (2015). Are there subtypes of panic disorder? An interpersonal perspective. Journal of Consulting and Clinical Psychology, 83, 938-950. http://dx.doi.org/10.1037/a0039373. 